\title{
Erratum to: Open-source, small-animal magnetic resonance-guided focused ultrasound system
}

\author{
Megan E. Poorman ${ }^{1 *}$, Vandiver L. Chaplin ${ }^{1,3}$, Ken Wilkens ${ }^{2}$, Mary D. Dockery ${ }^{1}$, Todd D. Giorgio ${ }^{1}$, \\ William A. Grissom ${ }^{1,2}$ and Charles F. Caskey ${ }^{2,4}$
}

\section{Erratum}

In the publication of this article [1] it was brought to our attention that one of the funding sources was incorrectly presented as DoD W81XW-12-BCRP-IDEA. This number is actually the granting mechanism and not the specific grant number.

The correct grant number should read W81XWH-131-0230, which is under the DoD BCRP-IDEA umbrella and should be the one mentioned in the Declaration section of this article.

\footnotetext{
Author details

${ }^{1}$ Department of Biomedical Engineering, Vanderbilt University, PMB 351631 2301 Vanderbilt Place, Nashville, TN 37235, USA. ${ }^{2}$ Institute of Imaging Science, Vanderbilt University, 1161 21st Avenue South, Nashville, TN 37232, USA. ${ }^{3}$ Chemical and Physical Biology Program, Vanderbilt University, 1161 21st Avenue South, Nashville, TN 37232, USA. ${ }^{4}$ Department of Radiology, Vanderbilt University, 1161 21st Avenue South, Nashville, TN 37232, USA.
}

Published online: 19 October 2016

\section{Reference}

1. Poorman ME, et al. Open-source, small-animal magnetic resonance-guided focused ultrasound system. J Ther Ultrasound. 2016;4:22. doi:10.1186/ s40349-016-0066-7.

\footnotetext{
* Correspondence: megan.poorman@vanderbilt.edu

${ }^{1}$ Department of Biomedical Engineering, Vanderbilt University, PMB 351631

2301 Vanderbilt Place, Nashville, TN 37235, USA

Full list of author information is available at the end of the article
} 